\title{
Analysis of the Riding Posture of Bicyclists and Influence Parameters on the Helmet Use
}

\author{
Dietmar Otte ${ }^{1}$, Thorsten Facius ${ }^{2}$ \\ ${ }^{1}$ Hannover Medical School, Hannover, Germany \\ ${ }^{2}$ Biomed-tec, Hannover, Germany \\ Email: otte.dietmar@mh-hannover.de,facius@biomed-tec.de
}

How to cite this paper: Otte, D. and Facius, T. (2017) Analysis of the Riding Posture of Bicyclists and Influence Parameters on the Helmet Use. Open Journal of Safety Science and Technology, 7, 58-68. https://doi.org/10.4236/ojsst.2017.71005

Received: March 6, 2017

Accepted: March 28, 2017

Published: March 31, 2017

Copyright ( 92017 by authors and Scientific Research Publishing Inc. This work is licensed under the Creative Commons Attribution International License (CC BY 4.0).

http://creativecommons.org/licenses/by/4.0/

cc) (i) Open Access

\begin{abstract}
In the scope of COST Action TU1101 a field study of the use of bicycle helmets was carried out and different seating positions of the human body on the cycle were analyzed from photos to identify the vertical vision limit due to the helmet geometry of the cyclists when riding a bicycle. It could be interesting to know if different helmet postures will influence the resulting head impact and head injury situation and which influence parameters are responsible for the decision of the cyclist to use or not to use a helmet. For the study helmet users are compared with non-helmet users, distinguished for different bicycle types. For this purpose a total of 1565 cyclists with and without helmets were photographed and relevant geometrical values such as the angle between seat and handle bar, the decline of the torso or the head posture and the angle of the vertical vision limit were established from the photo analysis. A significant variation of the sitting posture of the cyclist could be seen in field which is influenced by the bicycle type and the age group of the cyclist riding the bike. Even the helmet users showed slight differences in the head posture compared to non-helmet users.
\end{abstract}

\section{Keywords}

Bicycle Accident, Head Injury, Helmet, Riding Posture

\section{Introduction}

Within the COST Action TU1101 [1] acceptance criteria and problems in helmet use while bicycling are analysed, such as problems in conspicuity, thermal stress, ventilation deficits and other potential irritations.

Literature research showed no results for the topic of bicycle helmets and their influence on the head position, riding posture or a potential impaired vision for bicyclists wearing a helmet. In a questionnaire from the year 2014 conducted by 
the accident research unit at Hannover Medical School [2] 9\% of questioned bicycle users states that the helmet narrows their field of vision.

To analyse the helmet usage practice a study is conducted to analyse the posture of cyclists when riding a bicycle and whether the use of a bicycle helmet influences the seating geometry and whether the helmet vertically limits the vision.

For this purpose, cyclists with and without helmets were photographed in real world situations and relevant geometrical values such as the decline of the torso, the head posture of the upper vertical vision limit due to the helmet were established from the photos.

With the help of the pictures it is possible to define measurement lines on the body, the helmet and the bicycle which are influenced by the type of the bicycle and the wearing behavior of the bicycle helmets. This leads to the following methodology of this study.

\section{Data and Methodology for Obtaining the Riding Posture}

\subsection{Criteria and Methodology}

To identify the usage of a helmet and if the helmet has an influence on the seating posture of a cyclist in terms of a different seating position or head posture a survey was conducted in Germany, Finland, Greece, Turkey and Portugal by taking pictures of cyclists and analysing the seating geometry of riders out of these pictures.

Bicycle riders were photographed while riding the bicycle in a real world (non fictional) situation. The picture was taken anonymously from a large distance using a telephoto lens without the perception of the bicyclist. To be able to measure the seating posture correctly it was necessary to take pictures of cyclists riding rectangular to the photo axis (taking a picture exactly from the side of the cyclist). The type of bicycle was classified with the help of the photos into these subgroups:

- City bike: This category includes all kind of bicycles for everyday life, i.e. touring/trekking bikes, dutch bikes and children bikes.

- Mountain bike: A bike that is designed for use in off-road terrain like dirt, mud, snow and gravel. These bikes are built especially tough with thick tires and strong wheels that resist damage from impact. Mountain bikes usually feature flat handlebars.

- Racing bike: These bikes are built for high speed and for bicycle races. Distinguish marks are among others a lightweight construction with thin tires. Often a restriction on important parts can be recognized (missing of light, mudguard, pannier rack, etc.). The handlebar of racing bikes is often ergonomically formed.

- Other types: folding bikes, transport bikes, hybrid bikes, etc.

To analyse the pictures different geometrical values-had to be defined (see Figure 1). To define the seating geometry the sitting decline SD (angle of the cyclist's torso) and the angle between the handlebar and the seat HS were established for both riders with and without helmets. Subsequently the inclination of 
the line of the visual limit VL was investigated from pictures of riders using a helmet and the head posture HP was measured by the inclination of the line from the ear to the eye (see Figure 2).

At the pictures a horizontal reference line was established in a first step which was used as a base line to measure the different angles (see red line in Figure 1). A possible reference for this purpose is the line between the two axles of the bicycle, but could also be a horizontal line of building if e.g. the axles of the bicycle wheels are not visible on the photo.

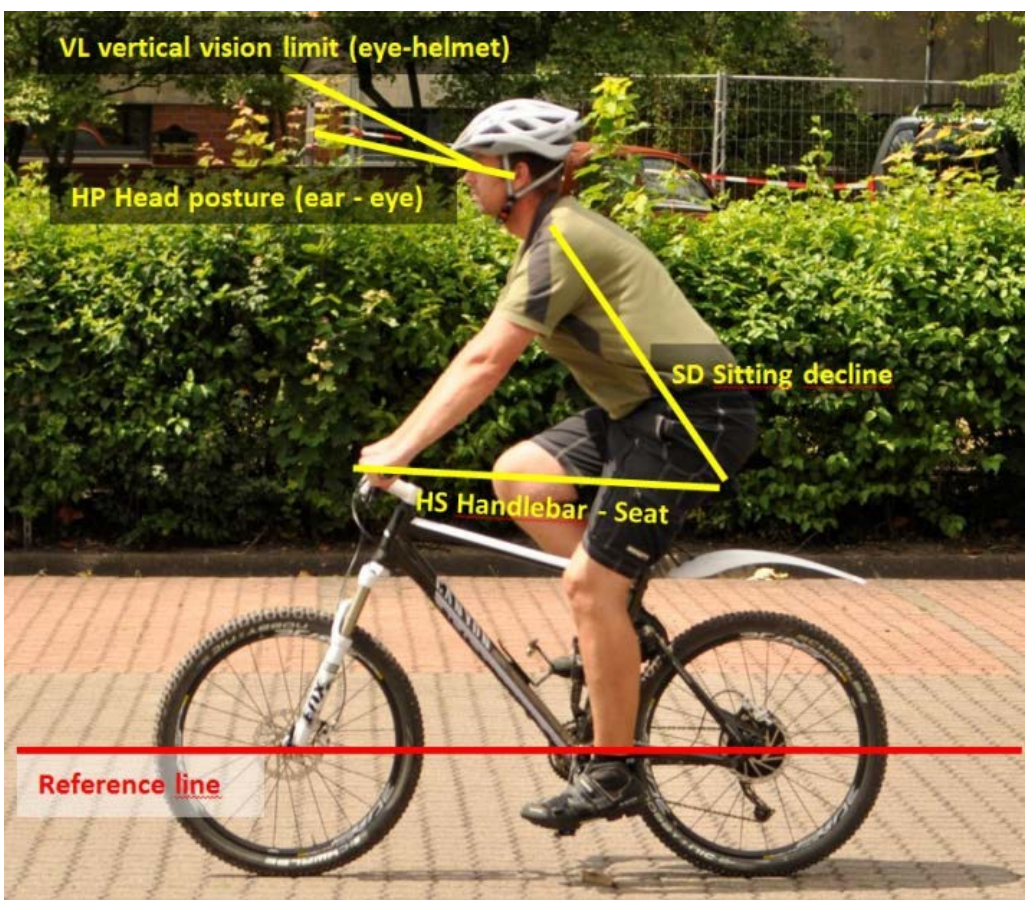

Figure 1. Establishment of angels relevant for seating geometry and vision limits.

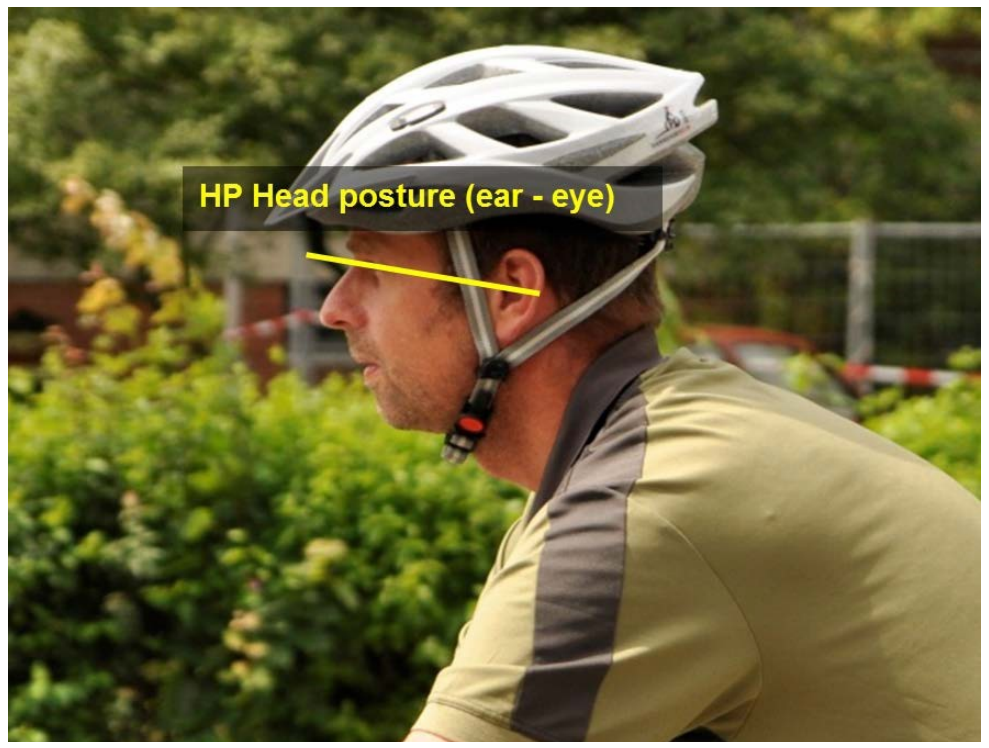

Figure 2. Establishment of the head posture angle by measuring the inclination of the line from the ear to the eye. 


\subsection{Resulting Data Sample}

In total 1,565 pictures were made in 5 different countries of Europe, covering north to south profiles, with the majority being cyclists without a helmet $(\mathrm{n}=$ 1231) compared to helmet wearers $(n=334)$. These numbers reflect the low helmet wearing rates, which are currently existent in the countries. Most were riding on city bikes $(\mathrm{n}=1027)$. Further common types were Mountain bikes ( $\mathrm{n}$ $=410)$ and Racing bikes $(\mathrm{n}=66)$. Other types of bicycles like folding bikes, transport bikes or hybrid bikes, which could not clearly be assigned to other groups were photographed in 62 cases only. The numbers of pictures is dominated by pictures from Germany ( $\mathrm{n}=1150$ of 1565 pictures). Here the pictures were mostly taken during normal working hours at a "bicycle path inner city" which represents a major bicycle path separated from other traffic and which connects an urban district with the city centre. The share of helmet wearers cannot be called representative because the focus of this study was set to collecting as many cyclists with a helmet as possible. The analysis of the cycle geometry shows that about the same amount of pictures of male riders with a helmet were taken as of female riders with a helmet (144 men; 140 women) and that in the group of riders without a helmet the amount of male riders $(n=643)$ was higher than the amount of female riders $(n=494)$. It has to be noted that the gender and the age group of the rider was estimated from the pictures. The share of the riders in the participating countries that had used a helmet for the age groups is shown in Table 1.

\section{Results}

For the following analysis the combined sample of pictures of all countries $(\mathrm{n}=$ 1565) was used because it is assumed that differences in postures are rather prone to different bicycle types than to the nationalities. The angle between the handlebar and the seat of the bicycle is a geometrical measure of the bike and influences the sitting posture. The cumulative frequency of this measure is shown in Figure 3 for the 3 most common types of bicycles i.e. city bike, mountain bike

Table 1. Share of helmet users among the photographed riders for different age groups in the participating countries. Number of riders with helmet and total number of riders are included in brackets.

\begin{tabular}{|c|c|c|c|c|c|c|}
\hline Age group & $\begin{array}{l}\text { Germany } \\
(\mathrm{n}=1150)\end{array}$ & $\begin{array}{l}\text { Finland } \\
(\mathrm{n}=107)\end{array}$ & $\begin{array}{l}\text { Greece } \\
(\mathrm{n}=157)\end{array}$ & $\begin{array}{l}\text { Turkey } \\
(\mathrm{n}=7)\end{array}$ & $\begin{array}{l}\text { Portugal } \\
(\mathrm{n}=144)\end{array}$ & $\begin{array}{c}\text { Total } \\
(\mathrm{n}=1565)\end{array}$ \\
\hline $\begin{array}{l}\text { younger } \\
18 \text { years }\end{array}$ & $\begin{array}{c}36 \% \\
\text { (4 from 11) }\end{array}$ & $\begin{array}{c}100 \% \\
\text { (5 from 5) }\end{array}$ & $\begin{array}{c}0 \% \\
\text { (o from 16) }\end{array}$ & n.a. & $\begin{array}{c}44 \% \\
\text { (4 from 9) }\end{array}$ & $\begin{array}{c}32 \% \\
(13 \text { from } 41)\end{array}$ \\
\hline $18-40$ years & $\begin{array}{c}16 \% \\
(84 \text { from } 528)\end{array}$ & $\begin{array}{c}100 \% \\
(71 \text { from } 71)\end{array}$ & $\begin{array}{c}2 \% \\
(2 \text { from } 82)\end{array}$ & $\begin{array}{c}57 \% \\
(4 \text { from } 7)\end{array}$ & $\begin{array}{c}33 \% \\
\text { (36 from 109) }\end{array}$ & $\begin{array}{c}25 \% \\
(197 \text { from } 799)\end{array}$ \\
\hline 41-65 years & $\begin{array}{c}11 \% \\
(55 \text { from } 492)\end{array}$ & $\begin{array}{c}100 \% \\
\text { (31 from 31) }\end{array}$ & $\begin{array}{c}2 \% \\
(1 \text { from } 54 \text { ) }\end{array}$ & n.a. & $\begin{array}{c}38 \% \\
(10 \text { from } 26)\end{array}$ & $\begin{array}{c}16 \% \\
\text { (97 from 603) }\end{array}$ \\
\hline 66 or older & $\begin{array}{c}23 \% \\
\text { (27 from 119) }\end{array}$ & n.a. & $\begin{array}{c}0 \% \\
\text { (O from 5) }\end{array}$ & n.a. & n.a. & $\begin{array}{c}22 \% \\
(27 \text { from } 124)\end{array}$ \\
\hline
\end{tabular}




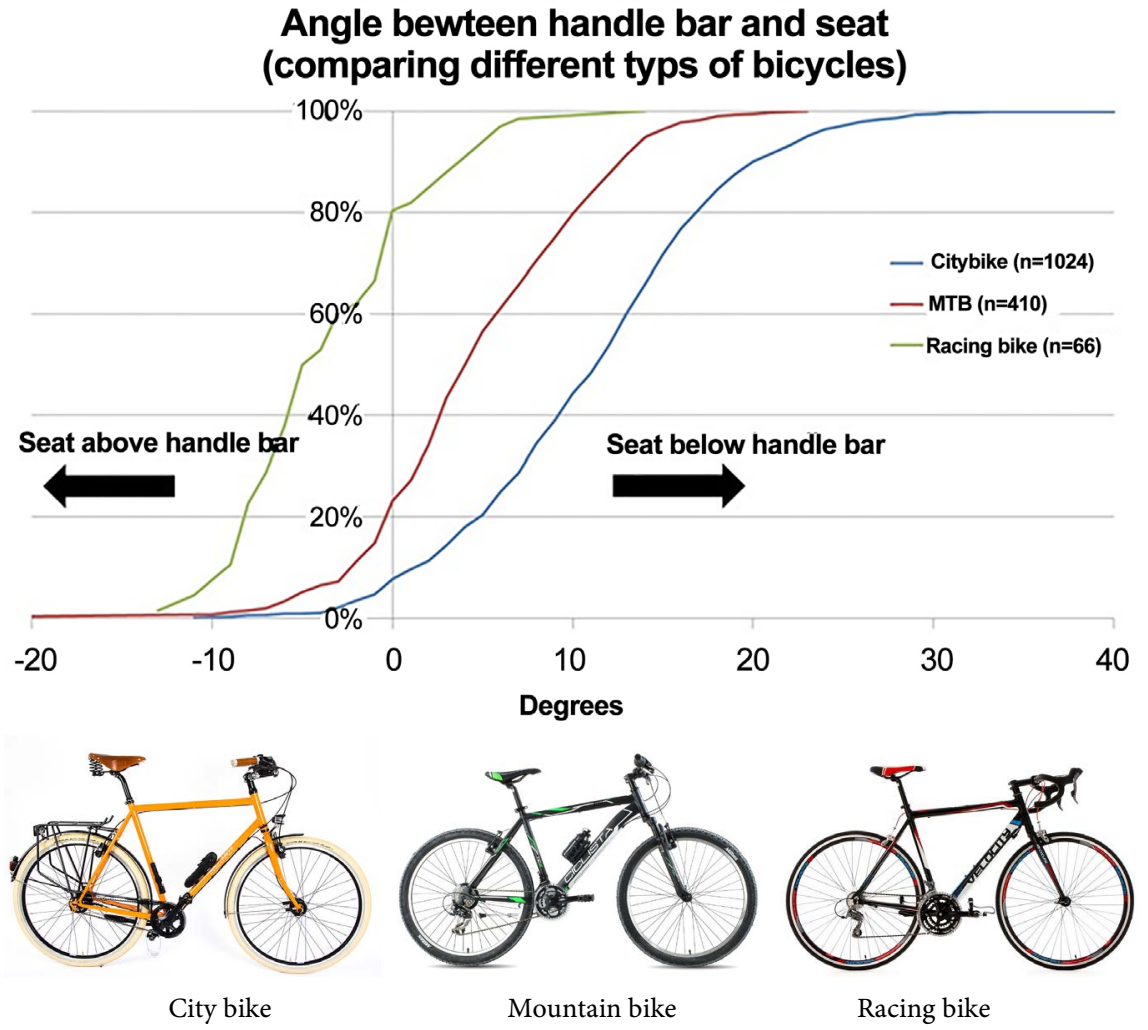

Figure 3. Angle between handle bar and seat for different types of bicycles.

and racing bike ( $\mathrm{p}<0.001$, One way analysis of variance). About $80 \%$ of the photographed racing bikes have their handle bar on a lower level than the seat, $20 \%$ even have a clearly higher seat than handle bar (angle HS of nearly $-10^{\circ}$ ). For mountain bikes this angle has a clear shift towards higher handle bars: About $80 \%$ have a handle bar on a higher level than the seat. City bikes have an even higher tendency towards higher handle bars and lower seats: In over $90 \%$ the handle bar was above the level of the seat and in about $60 \%$ of the pictures of city bikes the angle between handle bar and seat was $10^{\circ}$ or more.

As expected the geometrical measure of the angle between the handlebar and the seat has a clear influence on the sitting decline (the angle of the riders torso relative to the ground) which is displayed in Figure 4 ( $\mathrm{p}<0.001$, Oneway analysis of variance). About half of the riders of city bikes have a sitting decline of over $67^{\circ}$ and thus have a more upright torso than riders of mountain bikes where half of the riders have a sitting decline of under $58^{\circ}$ or than riders of racing bikes, where half of the riders have a sitting decline of $45^{\circ}$ or even less.

\section{Analysis of Influence of Helmet use on the Head Posture Based on Riders of City Bikes}

As the seating position of the bike rider is different when using different kind of bikes, it makes sense to analyze the influence of the helmet use on the head posture only using city bikes (with about $2 / 3$ of all bicycles the largest group) to exclude the influence of the posture difference by the bicycle type. 
The cumulative frequency of the Head posture (inclination of the line between the ear and the eye) for riders of city bikes only is displayed in Figure 5 for different age groups. It is interesting to see, that the age does not seem to have a large influence on the head posture of the riders ( $p=$ n.s., One way analysis of variance).

About half of the photographed riders of city bikes had an angle between the ear and the eye of less than $10^{\circ}$. In general it is presumed that the influences from the momentary head movements and the individual differences between of the angle between ear and eye of the people are compensated by the high number of evaluated photos.

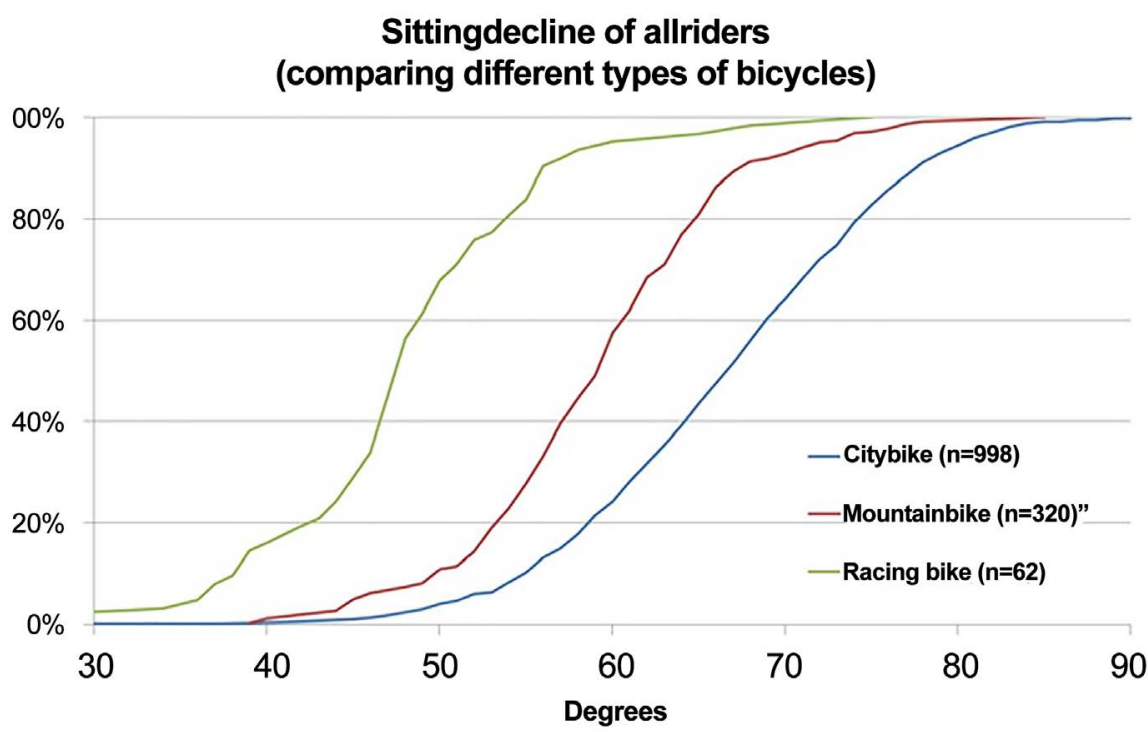

Figure 4. Sitting decline angle of the cyclist's torso for different types of bicycles.

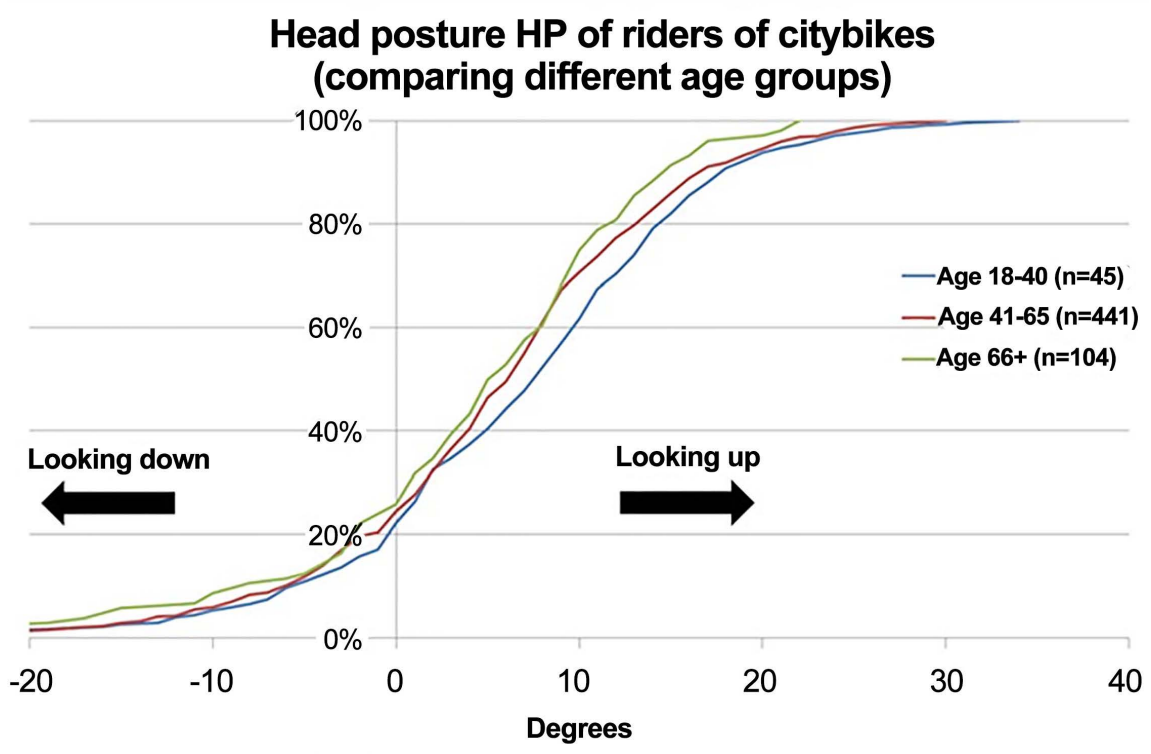

Figure 5. Head posture (inclination of the line from the ear to the eye) of riders of city bikes, comparing different age groups. 
The gender of the cyclist has in contrast to the age a significant influence on the head posture (see Figure 6) ( $\mathrm{p}<0.001$, t-test for independent groups). While half of the men have an inclination of the line between the ear and the eye which is lower than $4^{\circ}$, that of the women is about $5^{\circ}$ higher in average (50\% of women have a head posture of $9^{\circ}$ or higher). A possible explanation for this variation could be the slightly different posture of the upper body while riding: While male city bike riders have an average sitting decline of over $65^{\circ}$, the sitting decline of women was $68^{\circ}$ in average.

For the comparison of the head posture of riders with and without a helmet all age groups were taken due to the minor influence from the age of the riders $(\mathrm{p}=$ 0.026 , t-test for independent groups). Figure 7 displays the cumulative frequency of the head posture for city bike rides with a helmet and without a helmet. The helmet usage seems to have an influence especially on riders that have their head in a higher position. Here the riders with a helmet seem to lower their heads more than those without helmets: While $80 \%$ of the helmet users have a head posture of less than $10^{\circ}$, some $20 \%$ of the riders without a helmet have head postures of $14^{\circ}$ or more. The design of the helmet seems to have no significant influence on the head posture because most of the helmets are positioned on the head so that the front edge of the helmet sits close at the forehead above the eyes. Some exceptions are possible in female riders, which wear the helmet more in an upright position to protect their hairstyle.

In a further step the vertical vision limit VL due to the helmet was established for the city bike riders with helmets by constructing a line from the eye to the front rim of the helmet (usually the sun shade) at the moment when the picture was taken. The cumulative frequency of this angle for riders with a helmet of different age groups is shown in Figure 8 ( $\mathrm{p}=$ n.s., Oneway analysis of variance).

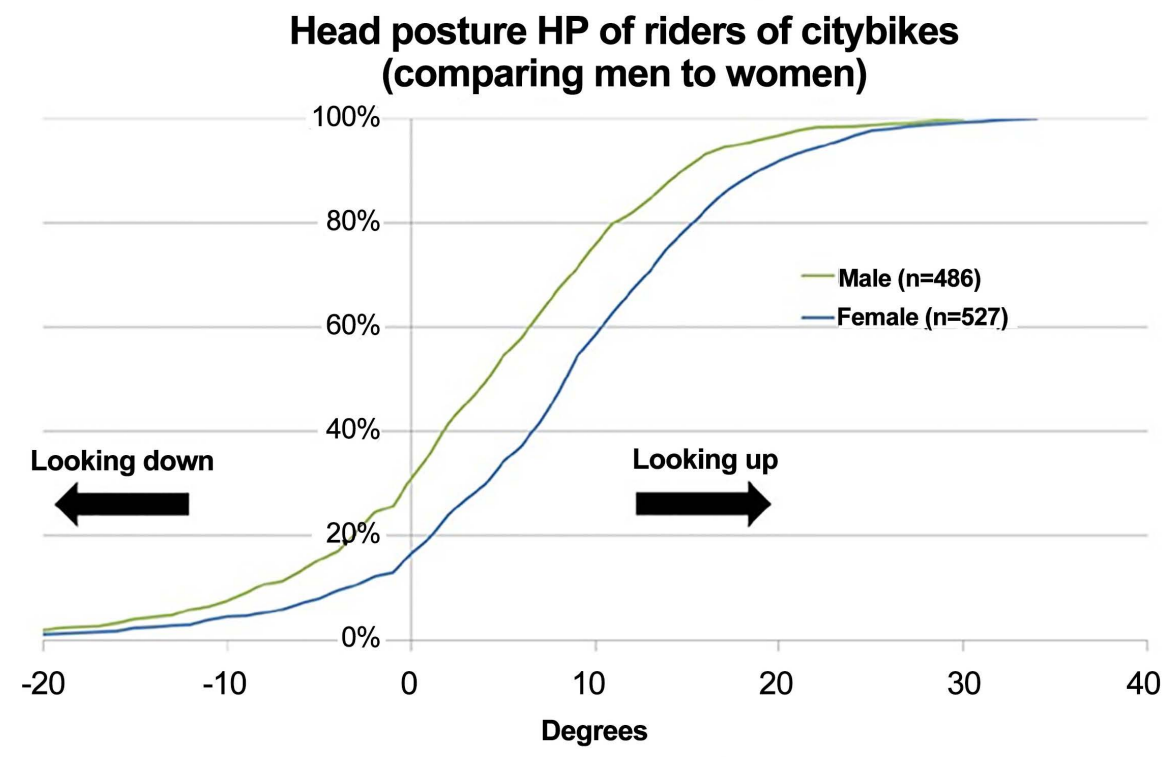

Figure 6. Head posture (inclination of the line from the ear to the eye) of riders of city bikes, comparing male to female riders. 


\section{Head posture HP of riders of citybikes \\ (comparing helmet users to non-users)}

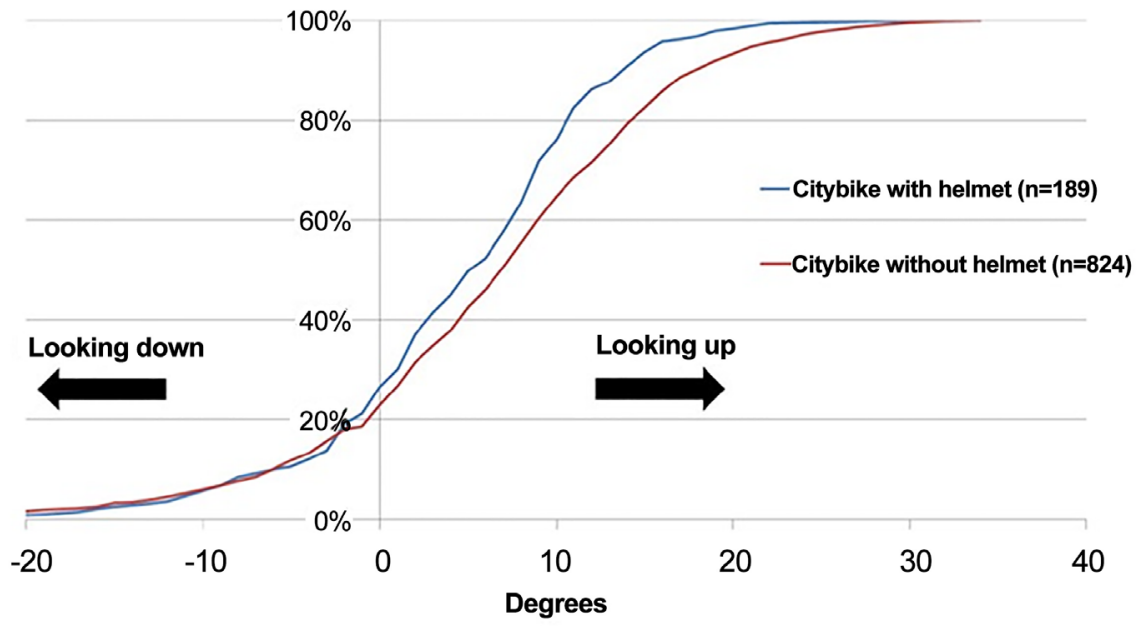

Figure 7. Head posture (inclination of the line from the ear to the eye) of riders of city bikes, comparing helmet users with non-users.

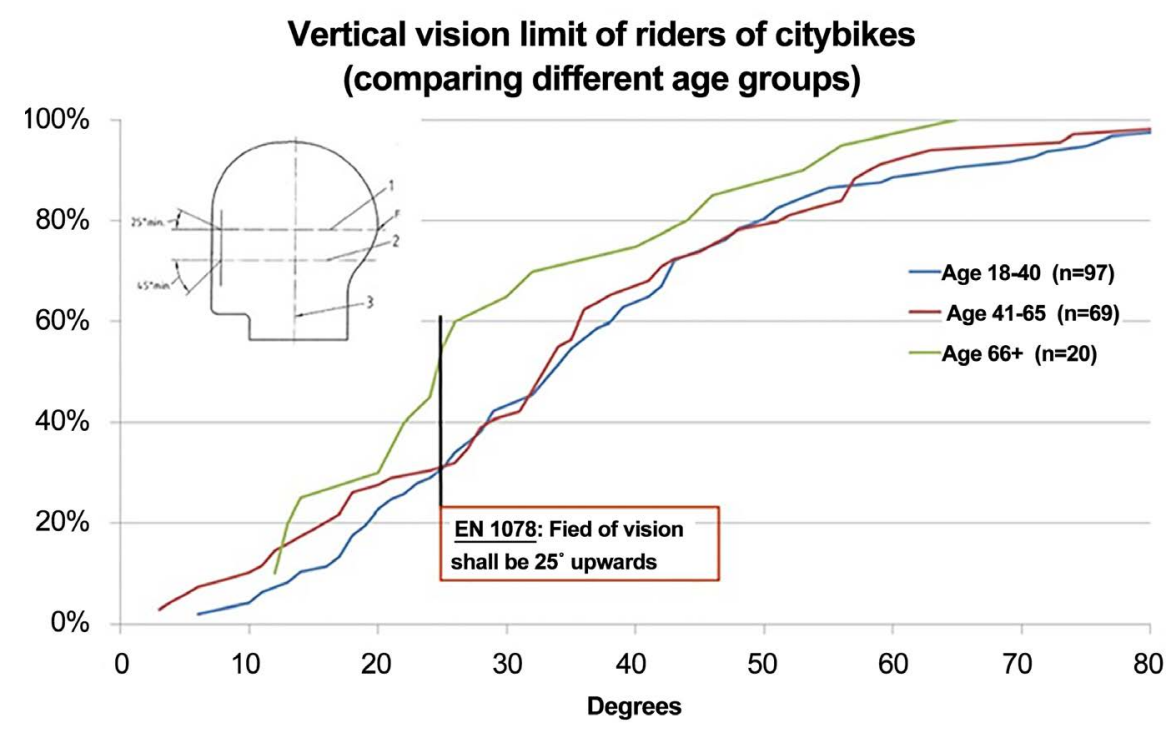

Figure 8. Vertical vision limit (vision limit upwards due to the helmet) of riders with helmets of city bikes, comparing different age groups. According to EN 1078, 4.3 no obstruction of vision may occur in an angle less than $25^{\circ}$ upwards to the horizontal reference plane.

Interestingly younger riders (18 - 65 years) have found to have a higher vision angle upwards than older riders aged 66 years or older: While half of the younger riders have a vision limit upwards of nearly 35 degrees, half of the older riders are just over 25 degrees and thus are at the limit of the upwards field of vision for cyclists with bicycle helmets when looking straight forward, as described in the standard EN 1078 [3]. So if the younger riders have a higher vision angle upwards than the older riders it can be assumed that older riders wear their helmets more turned forward into the face or have more helmets with a pronounced sun shade. However a higher field of vision can be contradictory to the 
area of protection. Especially the forehead is a major impact zone [4] and should have an optimized shock protection.

Regarding the gender it can be seen that female bicyclists used the helmet in a more upright position on the head so the vertical vision limit is higher compared to male riders (mean value female riders 38.9 degree; mean value male riders 26.6 degree).

\section{Conclusions}

A survey by taking pictures from bicycle riders in standard traffic situations during driving was carried out. Literature research showed no results for this topic. Therefore in total 1565 pictures of bicycle riders were taken from the participating partners across Europe. The methodology of analyzing the photos was developed by the researchers and characteristics could be analyzed.

Riders using a city bike had in average adjusted the handle bar higher above the seat than riders of mountain bikes and especially than riders of racing bikes which had the lowest incline between the handle bar and the seat. The posture of the upper body (sitting decline) correlated rather well with the incline of the line between the handle bar and the seat and was the highest for the riders of city bikes (the majority on the group of cyclists) with a sitting decline of over $67^{\circ}$ for half of the riders.

For the analysis of the influence of helmet use on the head posture (inclination of the line from the ear to the eye) only the largest group of riders (city bikes) was analysed. Here the age did not seem to have substantial influence on the head posture of the riders. However, male riders do look down a bit more than female riders ( $5^{\circ}$ on average). The age and the gender of the cyclist do seem to have an influence on the head posture. While half of the men have an inclination of the line between the ear and the eye which is lower than $4^{\circ}$ that of the women is about $5^{\circ}$ higher in average (50\% of women have a head posture of $9^{\circ}$ or higher). A possible explanation for this variation could be the slightly different posture of the upper body while riding: while male city bike riders have an average sitting decline of over $65^{\circ}$, the sitting decline of women was $68^{\circ}$ in average.

The helmet usage also seems to have an influence on the head posture: especially riders that have their head in a higher position seem to lower their head more when using a helmet than those without helmets: while $80 \%$ of the helmet users have a head posture of less than $10^{\circ}$ (between ear and eye), some $20 \%$ of the riders without a helmet have head postures of $14^{\circ}$ or more.

The vertical vision limit, which describes the vision limit upwards due to the helmet front (e.g. sun shade) was found to be influenced by the riders age. Older riders seem to wear their helmets more turned forward into the face or have more helmets with a pronounced sun shade: while half of the younger riders have a vision limit upwards of nearly 35 degrees, half of the older riders are just over 25 degrees. However, a higher field of vision can be contradictory to the area of protection of the helmet. Especially the forehead is a major impact zone 
[4] and should have an optimized shock protection.

Under the point of optimized protection the results of the study showed that there are differences in the helmet wearing behavior which can influence the protection of the head especially of the face. Female riders are possibly under a higher risk for head injuries (due to a higher head posture) and younger riders of city bikes (because an often observed higher vision angle seems contradictory to the helmet protection potential). While riders of racing bikes use a larger part of the protection zone (due to a lower head position when riding).

In summary the seating position on the bicycle is influencing the head posture while driving and therefore also the head position which is influencing the vertical vision limit $(\mathrm{VL})$ of the bicyclists. Regarding the gender it can be seen that female bicyclists use the helmet in a more upright position on the head so the vertical vision limit is higher compared to male riders (mean value female riders 38.9 degree; mean value male riders 26.6 degree). As well the kind of bicycle is influencing the seating position on the bicycle and therefore also the head position. For riders of city bikes a vertical vision limit angle of 27.9 degree for men and 39.8 degree for women could be detected. For riders of mountain bikes the vertical vision limit was lower (men: 25.7 degree vs. women: 37.4 degree) and lowest for racing bikes (men: 24.7 degree vs. women: 29.0 degree.

\section{Limitations of This Study}

People constantly move their heads when riding a bicycle. The pictures taken of these cyclists can only give a momentary position of the head. Due to the number of pictures taken and analyzed these effects are compensated only to a certain degree. Further it is possible to identify on the pictures whether the helmet is used correctly, however the correct use of the chin strap cannot be identified on the pictures. Additionally the location of the photo (incline or decline) may have in influence on the seating position of the cyclist. This fact was not taken into account. The vast majority of the analyzed pictures were from the city of Hannover where no relevant slope of the cycle path was present and the pictures were taken anonymously without speaking to the cyclists. Additionally it has to be mentioned that the majority of bicycles were city bikes because of the photo locations mostly in urban areas. Furthermore the effects from specific terrain, lights/signals/traffic, time of day and sun position were not taken into account in this study.

\section{Acknowledgements}

The study was carried out within the EU founded research project of COST TU 1407 by

- Members of Working Group 1 as listed here with names and institutes. The authors of this manuscript appreciate their work and describe their common efforts.

- M. Jänsch (Accident Research Unit, Hannover Medical School, Carl-Neuberg-Str. 1, 30625 Hannover, Germany) 
- Morandi, C. Orsi, A. Stendardo (3 Centre of Study and Research on Road Safety, University of Pavia, Via Forlanini 2, 27100 Pavia, Italy)

- G. Tzamalouca, M. Papadakaki, J. Chliaoutakis (Technological Educational Institute of Crete P. O. Box 1939, Estavromenos 71004)

- K. Parkkari (Heraklion, Greece, 5 Finnish Motor Insurers' Centre)

- J. Dias (Technical University of Lisbon, Av. RoviscoPais, 1049-001 Lisbon)

- T. Weber (Accident Research AGU, Winkelriedstrasse 27, CH-8006 Zürich, Switzerland)

\section{References}

[1] Bogerd, C.P., Annaheim, S., Halldin, P., Houtenbos, M., Otte, D., Shinar, D., Walker, I. and Willinger, R. (2015) HOPE: Helmet Optimization in Europe. The Final Report of COST Action TU1101, Brussels, Belgium. http://www.bicycle-helmets.eu

[2] Jänsch, M. and Otte, D. (2014) Cyclist-Reported Habits of Helmet Usage and Differences in Riding Postures by Using Helmets. Expert Symposium on Accident Research $(E S A R)$, Hannover.

[3] European Committee for Standardization (2012) EN 1078 Helmets for Pedal Cyclists and for Users of Skateboards and Roller Skates.

[4] Otte, D. and Haasper, C. (2010) Effectiveness of the Helmet for Bicyclists on Injury Reduction in German Road Accidents-State of Affairs on In-Depth-Study GIDAS. International Journal of Crashworthiness, 15, 211-221. https://doi.org/10.1080/13588260903102484

\section{Scientific Research Publishing}

Submit or recommend next manuscript to SCIRP and we will provide best service for you:

Accepting pre-submission inquiries through Email, Facebook, LinkedIn, Twitter, etc. A wide selection of journals (inclusive of 9 subjects, more than 200 journals)

Providing 24-hour high-quality service

User-friendly online submission system

Fair and swift peer-review system

Efficient typesetting and proofreading procedure

Display of the result of downloads and visits, as well as the number of cited articles

Maximum dissemination of your research work

Submit your manuscript at: http://papersubmission.scirp.org/

Or contact ojsst@scirp.org 